
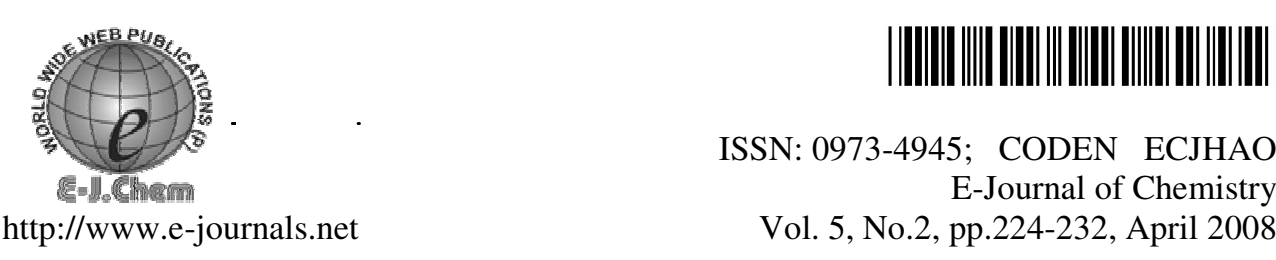

ISSN: 0973-4945; CODEN ECJHAO

E-Journal of Chemistry

Vol. 5, No.2, pp.224-232, April 2008

\title{
Removal of Phenol and $o$-Cresol by Adsorption onto Activated Carbon
}

\author{
A. EDWIN VASU \\ Post Graduate and Research Department of Chemistry, \\ St. Joseph's College (Autonomous), Tiruchirappalli-620 002, Tamil Nadu, India. \\ vasusjc@yahoo.co.in
}

Received 25 July 2007; Accepted 20 September 2007

\begin{abstract}
A commercial activated carbon was utilized for the adsorptive removal of phenol and $o$-cresol from dilute aqueous solutions. Batch mode adsorption studies were performed by varying parameters such as concentration of phenol solution, time, $\mathrm{pH}$ and temperature. The well known Freundlich, Langmuir and Redlich-Peterson isotherm equations were applied for the equilibrium adsorption data and the various isotherm parameters were evaluated. The Langmuir monolayer adsorption capacities were found to be 0.7877 and $0.5936 \mathrm{mmole} / \mathrm{g}$, respectively, for phenol and $o$-cresol. Kinetic studies performed indicate that the sorption processes can be better represented by the pseudo-second order kinetics. The processes were found to be endothermic and the thermodynamic parameters were evaluated. Desorption studies performed indicate that the sorbed phenol molecules can be desorbed with dil. HCl.
\end{abstract}

Keywords: Adsorption, Activated carbon, Phenol, $o$-Cresol, Adsorption kinetics, Isotherm

\section{Introduction}

Phenols and their derivatives are invariably present in the effluents from industries engaged in the manufacture of a variety of chemicals such as plastics, dyes, and in plants used for thermal processing of coal. Many of these phenols are carcinogens even when present in low concentrations. The presence of phenols in water also produces foul smelling chlorophenols during chlorination treatment of water for domestic supply.

Exposures to phenol can occur in workplace, from environmental media, from contaminated drinking water or foodstuff or from use of consumer products containing phenol $^{1}$. All routes readily absorb phenol: oral, inhalation, and dermal ${ }^{2}$. Phenol is a strong eye and respiratory irritant. It is corrosive to the eyes and skin upon direct contact. Human deaths have occurred following internal ingestion of large areas of skin $(>25 \% \text { of total })^{1}$. The minimum reported lethal dose in humans ${ }^{3}$ was $4.8 \mathrm{~g}$ or approximately $70 \mathrm{mg} / \mathrm{Kg}$. 
The worldwide production of $o$-cresol is approximately 37000-38000 tones/annum. It is mainly used as an intermediate for the production of pesticides, herbicides, rubber and plastics, antioxidants, deodourizing and fragrances, epoxy resins, dyes, and pharmaceuticals and also as a component of disinfectants and cleaning agents. $O$-Cresol is toxic to fish, aquatic plants, microorganisms, soil dwelling organisms, terrestrial plants and also to humans.

The Indian Standard specifications ${ }^{4}$ for drinking water has set the maximum allowable limit of $0.001 \mathrm{ppm}$ for phenols. It is therefore necessary to reduce or eliminate phenols from water and wastewater. Though bioaccumulation and biosorption are mainly preferred for this task as the phenols are easily biodegradable, adsorption onto activated carbon is also effective. Many works have been reported in the adsorptive removal of phenolics from aqueous solutions $^{5-11}$. The removal efficiency of a commercial activated carbon (M/s. Loba Company, Mumbai) towards phenol and $o$-cresol was attempted in the present study. The effects of adsorbate dose, $p \mathrm{H}$, time and temperature were studied.

\section{Experimental}

\section{Adsorbent}

The granular activated carbon supplied by M/s. Loba Company, Mumbai was used in this study. The carbon was ground and the portion retained between 150 and $250 \mu \mathrm{m}$ sieves was used for study. The adsorbent was named as CC. The characteristics of the carbon were reported elsewhere ${ }^{12}$.

\section{Analysis of phenol and o-cresol}

Both phenol and $o$-cresol were analyzed spectrophotometrically by monitoring their absorption at $270 \mathrm{~nm}$.

\section{Equilibrium adsorption experiments}

All the equilibrium adsorption experiments comprised three replicate $100 \mathrm{~mL}$ glassstoppered bottles containing selected amount of adsorbent and $50 \mathrm{~mL}$ of adsorbate solutions of selected concentrations. Control flasks without the adsorbents are also prepared simultaneously. Mixtures were maintained in a rotary shaker (Orbitek, Chennai, India) at constant temperature $\left(30,45\right.$ or $\left.60^{\circ} \mathrm{C}\right)$. After the attainment of equilibrium the contents of each flask were filtered through Whatmann No.41 filter paper, with the first $10 \mathrm{~mL}$ discarded. The filtered samples were then analyzed for unadsorbed phenols.

\section{pH variation studies}

In order to find out the optimum $\mathrm{pH}$ for maximum removal of phenols, experiments were carried out with solutions of same phenol concentration but adjusted to different initial $p \mathrm{H}$ values (with $\mathrm{HNO}_{3}$ or $\mathrm{NaOH}$ ).

\section{Desorption Studies}

After equilibrium adsorption, the phenols loaded carbons were separated and washed gently with several portions of distilled water to remove any unadsorbed species. The samples were then air-dried and agitated with $0.1 \mathrm{M}$ solutions of $\mathrm{HCl}, \mathrm{AcOH}$ or water for a period of 10 hours and the amounts of desorbed species were determined in the usual way.

\section{Results and Discussion}

Equilibrium studies

The isotherm plots obtained for the adsorption of phenol and $o$-cresol are shown in Figure 1. The isotherms were of L2 type under Giles ${ }^{13}$ classification. 


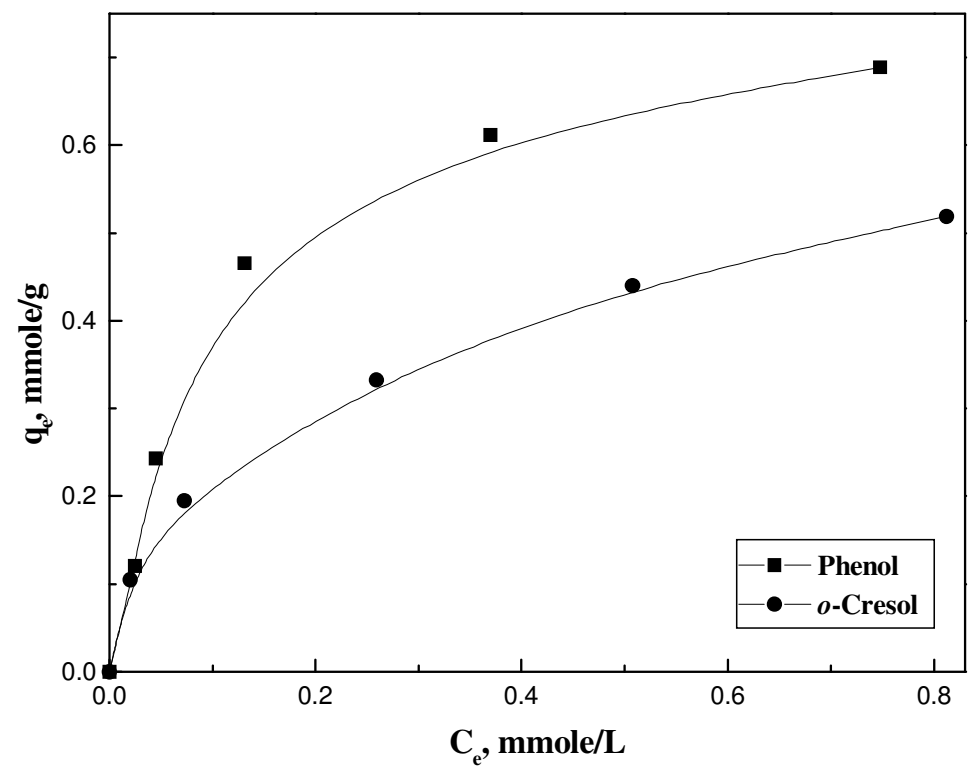

Figure 1. Isotherm plots for adsorption of phenol and $o$-cresol on activated carbon

The equilibrium adsorption data obtained were then fitted to Freundlich, Langmuir and Redlich-Peterson isotherm ${ }^{14}$ equations:

$$
\begin{array}{ll}
\text { Freundlich } & q_{e}=K_{F} C_{e}^{(1 / n)} \\
\text { Langmuir } & q_{e}=K_{L} C_{e} /\left(1+b C_{e}\right)=q_{m} b C_{e} /\left(1+b C_{e}\right) \\
\text { RedlichPeterson } & q_{e}=K_{R} C_{e} /\left(1+b_{R} C_{e}{ }^{\beta}\right)
\end{array}
$$

Where $q_{e}$ is the adsorption capacity in $\mathrm{mg} / \mathrm{g} ; C_{e}$ is the equilibrium concentration of adsorbate $(\mathrm{mg} / \mathrm{L}) ; K_{F}$ and $\mathrm{n}$ are Freundlich constants; $K_{L}$ and $b$ are Langmuir constants; $q_{m}$ is the Langmuir monolayer adsorption capacity and $K_{R}, b_{R}$ and $\beta$ are Redlich-Peterson isotherm constants. The equilibrium data obtained were fitted to the above three isotherm equations separately and the

\begin{tabular}{|c|c|c|c|c|c|c|}
\hline \multirow{3}{*}{ Adsorbate } & \multirow{3}{*}{ Model } & \multicolumn{5}{|c|}{ Model parameters } \\
\hline & & \multicolumn{2}{|c|}{$K_{F}$} & \multirow{2}{*}{$1 / n$} & \multirow{2}{*}{$n$} & \multirow{2}{*}{$r^{2}$} \\
\hline & & $\mathrm{mmol} / \mathrm{g}$ & $\mathrm{mg} / \mathrm{g}$ & & & \\
\hline \multirow{2}{*}{$\begin{array}{l}\text { Phenol } \\
o \text {-Cresol }\end{array}$} & \multirow{2}{*}{ Freundlich } & 0.8201 & 14.2430 & 0.3719 & 2.6889 & 0.9594 \\
\hline & & 0.5733 & 8.9307 & 0.4137 & 2.4172 & 0.9991 \\
\hline \multirow{2}{*}{ Adsorbate } & \multirow{2}{*}{ Model } & \multicolumn{5}{|c|}{ Model parameters } \\
\hline & & $K_{L}$ & $b$ & & $q_{m}$ & $r^{2}$ \\
\hline \multirow{2}{*}{$\begin{array}{l}\text { Phenol } \\
o \text {-Cresol }\end{array}$} & \multirow{2}{*}{ Langmuir } & 7.7014 & 9.7773 & & 0.7877 & 0.9965 \\
\hline & & 3.6658 & 6.1756 & & 0.5936 & 0.9852 \\
\hline \multirow{2}{*}{ Adsorbate } & \multirow{2}{*}{ Model } & \multicolumn{5}{|c|}{ Model parameters } \\
\hline & & $K_{R}$ & $b_{R}$ & & $\beta$ & $\mathrm{r}^{2}$ \\
\hline Phenol & Redlich- & 6.8139 & 8.8798 & & 1.0858 & 0.9976 \\
\hline$o$-Cresol & Peterson & 17.8209 & 30.6469 & & 0.6472 & 0.9999 \\
\hline
\end{tabular}
parameters evaluated are presented in Table 1 along with the correlation coefficient values for each fit.

Table 1. Isotherm parameters for the adsorption of phenols on $\mathrm{CC}$ at $30^{\circ} \mathrm{C}$ 
It is evident from Table 1 that of the three isotherm models used it is the threeparameter Redlich-Peterson model that fits the experimental data with best correlation coefficient values. This is expected as the Redlich-Peterson equation has three fitting parameters, especially with $\beta$ being a more direct parameter for adsorbate-adsorbent interaction strength.

The Langmuir monolayer capacity, $K_{L}$ was higher for phenol than $o$-cresol. A possible explanation can be given by invoking a 'bottle-neck' model for the pores present on the adsorbents' surface. According to this model, the pores resemble bottles in that they have very small openings like bottlenecks. After an appropriate monolayer outer surface coverage, there will be a certain population of phenol molecules at the pore entrance and as there are no substituents on the benzene ring of phenol, the pore entrance is relatively free for the movement of other unadsorbed phenol molecules into the pores. Therefore, more and more of phenol molecules can diffuse and subsequently be adsorbed in pores. But the situation for the adsorption of $o$-cresol is somewhat different in that the methyl groups of adsorbed $o$-cresol molecules may block the pore openings. Transport of unadsorbed cresol molecules from solution into the pores, therefore, is hindered which leads to lesser filling of pores. The overall amount of adsorbed cresol is thus less than that of phenol.

The Langmuir $b$ values determined are further used to calculate the dimensionless separation factor, $R_{L}{ }^{15}$, 16 , defined as

$$
R_{L}=1 /\left(1+b C_{i}\right)
$$

where $C_{i}$ is the initial solute concentration. The RL values calculated are listed in Table 2.

Table 2. $\mathrm{R}_{\mathrm{L}}$ values for the adsorption of phenols on $\mathrm{CC}$ at $30^{\circ} \mathrm{C}$

\begin{tabular}{ccc}
\hline Adsorbate & $\begin{array}{c}C_{i} \\
\mathrm{mg} / \mathrm{L}\end{array}$ & $\mathrm{R}_{\mathrm{L}}$ value \\
\hline \multirow{3}{*}{ Phenol } & 25 & 0.0041 \\
& 50 & 0.0020 \\
& 100 & 0.0010 \\
& 150 & 0.0007 \\
$o$-Cresol & 200 & 0.0005 \\
\hline & 25 & 0.0064 \\
& 50 & 0.0032 \\
& 100 & 0.0016 \\
& 150 & 0.0011 \\
\hline
\end{tabular}

The magnitude of $R_{L}$ value gives an idea about the nature of adsorption equilibrium: the process is non-spontaneous when $R_{L}$ is greater than one; favorable when $R_{L}$ lies between 0 and 1; and irreversible when $R_{L}$ is zero. In all the systems studied, $R_{L}$ values were comprised between 0 and 1 indicating favorable on the activated carbon.

\section{Effect of $p H$}

The effect of $\mathrm{pH}$ of solution on the adsorption percentage of phenol and $o$-cresol is shown in Figure 2. There is no significant change in the amount of adsorption with respect to change in the solution $\mathrm{pH}$. But the very slight decrease in the adsorption extent is noted with respect to increase in solution $\mathrm{pH}$. This could be due to the increased solubility of phenol molecules at alkaline conditions, which results in greater affinity for the phenol molecules to remain in solution rather than to get adsorbed onto the carbon surface. 


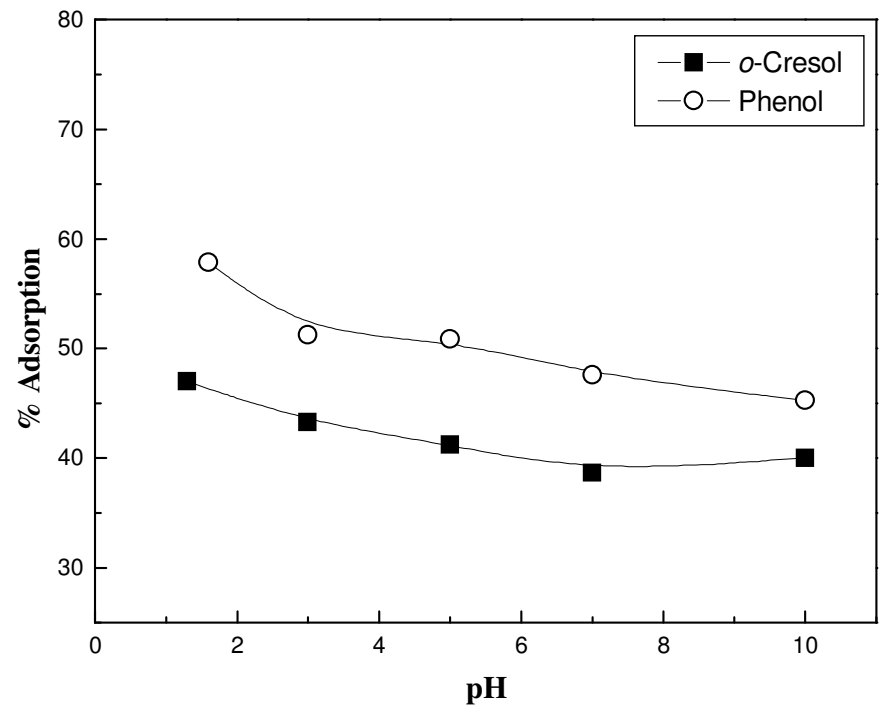

Figure 2. Effect of $\mathrm{pH}$ on the adsorption of phenols on $\mathrm{CC}$

\section{Adsorption kinetics}

The kinetic behavior as shown in Figure 3 is fitted to the following three rate equations reported in the literature, namely, first order model ${ }^{17}$, pseudo-second order model ${ }^{18-20}$ and the Elovic model ${ }^{21-22}$.

$$
\begin{array}{ll}
\text { First order rate equation } & \log \left(q_{e(1)}-q_{t}\right)=\log q_{e(1)}-k_{1} t \\
\text { Second order rate equation } & t / q_{t}=(1 / h)+\left(1 / q_{e(2)}\right) t \\
\text { Elovic equation } & q_{e}=\left(1 / \beta_{E}\right) \ln \left(\alpha \beta_{E}\right)+\left(1 / \beta_{E}\right) \ln t
\end{array}
$$

where, $\quad q_{t}=$ amount adsorbed at time $t, \mathrm{mg} / \mathrm{g}$

$q_{e}=$ amount adsorbed at equilibrium, $\mathrm{mg} / \mathrm{g}$

$q_{e(1)}=$ adsorption capacity predicted by the I order model, $\mathrm{mg} / \mathrm{g}$

$k_{1}=$ first order rate constant $\left(\mathrm{min}^{-1}\right)$

$k_{2}=$ second order rate constant $\left(\mathrm{gmg}^{-1} \mathrm{~min}^{-1}\right)=h / q_{e(2)}{ }^{2}$

$q_{e(2)}=$ adsorption capacity predicted by the II order model, $\mathrm{mg} / \mathrm{g}$

$\alpha($ Elovic model $)=h($ II order model $)=$ initial sorption rate $\left(\mathrm{mgg}^{-1} \mathrm{~min}^{-1}\right)$

$\beta=$ desorption constant $\left(\mathrm{gmg}^{-1}\right)$

$t=$ contact time, $\min$

The parameters evaluated for the three rate models were shown in Tables 3, 4 and 5. It is observed that both the first order and the Elovic model are quite inefficient than the pseudo-second order rate equation (inferred from the $r^{2}$ values) in predicting correctly the sorption dynamics. It is to be noted that the $q_{e}$ values predicted by the second order model agree very closely to the experimental values.

Table 3. First order parameters for the adsorption of phenols on CC

\begin{tabular}{ccccc}
\hline \multirow{2}{*}{ Adsorbate } & \multicolumn{2}{c}{$\begin{array}{c}\text { Equilibrium uptake } \\
\mathrm{mg} / \mathrm{g}\end{array}$} & \multirow{2}{*}{$\begin{array}{c}k_{1} \\
\min ^{-1}\end{array}$} & $\mathrm{r}^{2}$ \\
\cline { 2 - 3 } & $q_{e(1)}$ & $q_{e(\exp )}$ & & \\
\hline Phenol & 35.6041 & 43.8300 & 0.0048 & 0.9848 \\
$o$-Cresol & 25.6035 & 35.9800 & 0.0074 & 0.9721 \\
\hline
\end{tabular}




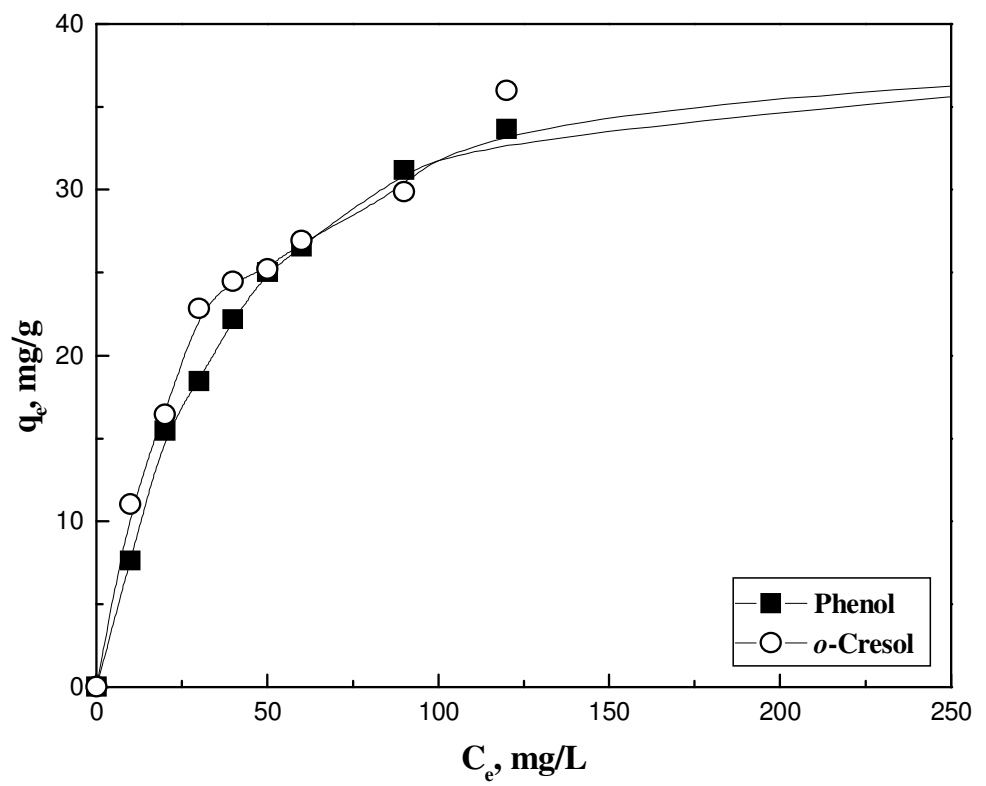

Figure 3. Kinetic curves for adsorption of phenols on $\mathrm{CC}$

Table 4. Pseudo-second order parameters for the adsorption of phenols on CC

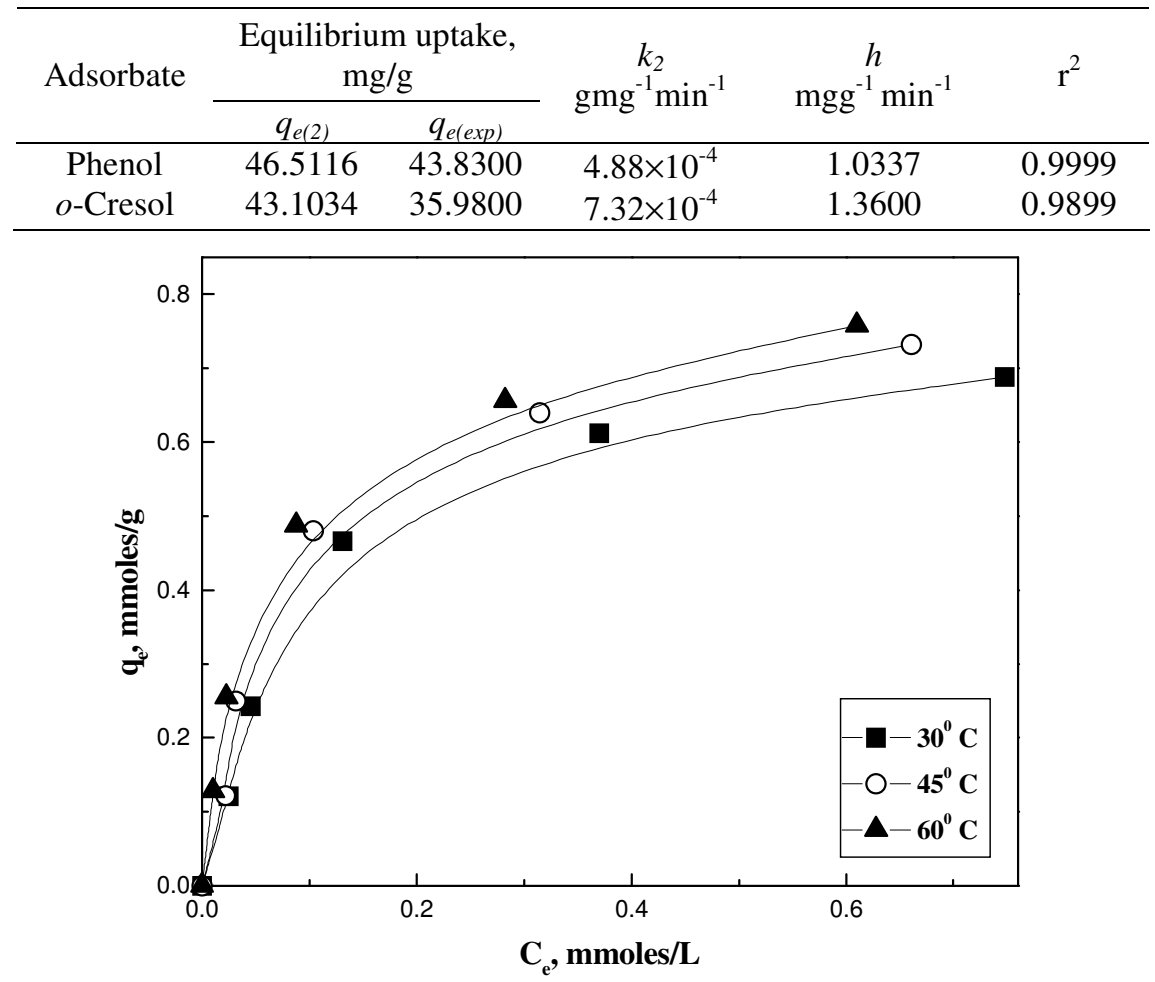

Figure 4. Adsorption of phenol on CC: Effect of temperature 
Table 5. Elovic parameters for the adsorption of phenols on CC

\begin{tabular}{ccccc}
\hline Adsorbate & $\alpha$ & $\alpha \beta_{E}$ & $\beta_{E}$ & $\mathrm{r}^{2}$ \\
\hline Phenol & 0.8654 & 6.3199 & 7.3029 & 0.9936 \\
$o$-Cresol & 0.1192 & 0.3376 & 2.8322 & 0.9866 \\
\hline
\end{tabular}

\section{Effect of temperature}

The adsorption of phenols on CC increased with increase in temperature (Figure 4), suggesting that these processes are endothermic. The isotherm parameters for the equilibrium at temperatures of 45 and $60^{\circ} \mathrm{C}$ are presented in Tables 6 and 7. It can be seen from Tables 6 and 7 that the value of $q_{m}$ decreases and $K_{L}$ increases for the adsorption of phenols on $\mathrm{CC}$ with increase in adsorption temperature.

Table 6. Isotherm parameters for adsorption of phenols on $\mathrm{CC}$ at $45^{\circ} \mathrm{C}$

\begin{tabular}{|c|c|c|c|c|c|}
\hline \multirow{2}{*}{ Adsorbate } & \multirow{2}{*}{ Model } & \multicolumn{4}{|c|}{ Model parameters } \\
\hline & & $K_{F}$ & $1 / n$ & $n$ & $\mathrm{r}^{2}$ \\
\hline \multirow{2}{*}{$\begin{array}{c}\text { Phenol } \\
o \text {-Cresol }\end{array}$} & \multirow{2}{*}{ Freundlich } & 0.9071 & 0.3662 & 2.7307 & 0.9579 \\
\hline & & 0.7427 & 0.4161 & 2.4033 & 0.9920 \\
\hline \multirow{2}{*}{ Adsorbate } & \multirow{2}{*}{ Model } & \multicolumn{4}{|c|}{ Model parameters } \\
\hline & & $K_{L}$ & $b$ & $q_{m}$ & $r^{2}$ \\
\hline \multirow{2}{*}{$\begin{array}{l}\text { Phenol } \\
o \text {-Cresol }\end{array}$} & \multirow{2}{*}{ Langmuir } & 9.9407 & 12.0777 & 0.8321 & 0.9932 \\
\hline & & 5.6187 & 8.0904 & 0.6945 & 0.9964 \\
\hline \multirow{2}{*}{ Adsorbate } & \multirow{2}{*}{ Model } & \multicolumn{4}{|c|}{ Model parameters } \\
\hline & & $K_{R}$ & $b_{R}$ & $\beta$ & $r^{2}$ \\
\hline Phenol & Redlich- & 9.2157 & 11.4545 & 1.0499 & 0.9936 \\
\hline$o$-Cresol & Peterson & 0.6074 & 11.8087 & 0.8112 & 1.000 \\
\hline
\end{tabular}

Table 7. Isotherm parameters for adsorption of phenols on $\mathrm{CC}$ at $60^{\circ} \mathrm{C}$

\begin{tabular}{cccccc}
\hline \multirow{2}{*}{ Adsorbate } & \multirow{2}{*}{ Model } & \multicolumn{4}{c}{ Model parameters } \\
\cline { 3 - 6 } & & $K_{F}$ & $1 / n$ & $n$ & $\mathrm{r}^{2}$ \\
\hline Phenol & \multirow{2}{*}{ Freundlich } & 0.9429 & 0.3344 & 2.9904 & 0.9745 \\
$o$-Cresol & & 0.9511 & 0.4025 & 2.4847 & 0.9800 \\
Adsorbate & Model & \multicolumn{4}{c}{ Model parameters } \\
Phenol & \multirow{2}{*}{$K_{L}$} & $b$ & $q_{m}$ & $\mathrm{r}^{2}$ \\
$o$-Cresol & Langmuir & 14.8373 & 18.4473 & 0.8043 & 0.9979 \\
Adsorbate & Model & 9.3251 & 11.8616 & 0.7862 & 0.9952 \\
Phenol & \multirow{4}{*}{$K_{R}$} & Model parameters & $b_{R}$ \\
$o$-Cresol & Redlich- & 17.7603 & 21.1440 & 0.9256 & 0.9993 \\
& Peterson & 11.5808 & 13.8700 & 0.8945 & 0.9966 \\
\hline
\end{tabular}

Van't Hoff equation, in the following form, was used to calculate the thermodynamic parameters such as Gibbs's free energy change $(\Delta \mathrm{G})$, enthalpy change $(\Delta \mathrm{H})$ and entropy change $(\Delta S)$ :

$$
\log K_{C}=\left[\frac{\Delta S}{2.303 R}\right]-\left[\frac{\Delta H}{2.303 R T}\right]
$$


Where $\mathrm{K}_{\mathrm{C}}$ is the equilibrium constant for the distribution of phenols between the liquid and solid phases; $\mathrm{T}$ is absolute temperature, ${ }^{\circ} \mathrm{K}$ and $\mathrm{R}$ the gas constant. Van't Hoff plots were constructed for each system and $\Delta \mathrm{H}$ and $\Delta \mathrm{S}$ were calculated from the slope and intercept of the plots, respectively (Table 8)

Table 8. Thermodynamic parameters for the adsorption of phenols on $\mathrm{CC}$

\begin{tabular}{|c|c|c|c|c|c|c|}
\hline \multirow{2}{*}{ Adsorbate } & \multirow{2}{*}{$\begin{array}{c}\mathrm{Ci}, \\
\mathrm{mg} / \mathrm{L}\end{array}$} & \multicolumn{3}{|c|}{$-\Delta \mathrm{G}, \mathrm{kJ} \mathrm{mol}^{-1}$} & \multirow{2}{*}{$\begin{array}{c}\Delta \mathrm{H} \\
\mathrm{kJmol}^{-1}\end{array}$} & \multirow{2}{*}{$\begin{array}{c}\Delta \mathrm{S} \\
\mathrm{JK}^{-1} \mathrm{~mol}^{-1}\end{array}$} \\
\hline & & $30^{\circ} \mathrm{C}$ & $45^{\circ} \mathrm{C}$ & $60^{\circ} \mathrm{C}$ & & \\
\hline \multirow{6}{*}{ Phenol } & 25 & 5.7554 & 6.3862 & 8.8305 & 25.0063 & 100.6221 \\
\hline & 50 & 5.9992 & 7.2935 & 8.6441 & 20.7088 & 88.1209 \\
\hline & 100 & 4.9391 & 5.8894 & 6.6618 & 12.4918 & 57.6195 \\
\hline & 150 & 3.0146 & 3.7106 & 4.2484 & 9.4749 & 41.3004 \\
\hline & 200 & 1.5384 & 2.1068 & 2.5174 & 8.3764 & 32.8029 \\
\hline & 25 & 5.8861 & 6.5299 & 7.7657 & 13.0020 & 62.0444 \\
\hline \multirow{4}{*}{$o$-Cresol } & 50 & 4.2388 & 5.6767 & 7.7481 & 31.1052 & 116.3342 \\
\hline & 100 & 2.3741 & 4.0396 & 5.5903 & 30.1346 & 107.3485 \\
\hline & 150 & 1.3876 & 2.6637 & 4.5603 & 30.5582 & 105.1236 \\
\hline & 200 & 0.6172 & 1.6221 & 2.7803 & 21.2088 & 71.9569 \\
\hline
\end{tabular}

\section{Desorption studies}

The results with water, $0.1 \mathrm{M}$ acetic acid and $0.1 \mathrm{M}$ hydrochloric acid are presented in Table 9. We are to understand that desorption increases with increase in the acidity of the desorbing medium; desorption is higher in hydrochloric acid than in acetic acid. This does not imply that the phenol molecules are adsorbed by an ion-exchange mechanism, but rather could be due to the increased solubility of the phenol molecules in the acidic media.

Table 9. Desorption of phenols

\begin{tabular}{lccc}
\hline \multirow{2}{*}{ Adsorbate } & \multicolumn{3}{c}{ \% Desorption with } \\
\cline { 2 - 4 } & Water & AcOH & HCl \\
\hline Phenol & 25.49 & 55.28 & 71.25 \\
$o$-Cresol & 24.05 & 51.29 & 70.28 \\
\hline
\end{tabular}

\section{Conclusions}

The work presented in this work has shown that the commercial activated carbon can be successfully used for the adsorptive removal of phenolic pollutants from water. The three-parameter Redlich-Peterson isotherm equation better represented the equilibrium adsorption data. Kinetic studies point to the fact that the sorption dynamics of phenols are predicted more accurately by the pseudo-second order rate model. $\mathrm{pH}$ has no significant role to play in the adsorptions and are found to be endothermic in nature. The thermodynamic parameters were evaluated.

\section{References}

1. Agency for Toxic Substances and Disease Registry (ATSDR) Toxicological Profile for Phenol. Atlanta, GA: Department of Health and Human Services; Public Health Service; Centers for Disease Control, 1998

2. Bruce R, Santodonata J and Neal M, Summary Review of the Health Effects Associated with Phenol Toxicology and Industrial Health. 1987, 3, 535-568

3. International Program on Chemical Safety (IPCS) Phenol. Environmental Health Criteria. 1994, 161. 
4. Indian Standards Specification for Drinking Water, Annexures VII and VIII, IS 10500, 1983

5. Knetting E, Thomson B M and Hurdey S E, Environ. Poll. B, 1986, 12(4), 281-299

6. Kumar S, Upadhyay S N and Upadhya Y D, J. Chem. Technol. Biotechnol. 1987, 37(4), 281-290

7. Bhandari A and Cho I., Proceedings of the 1999 conference on Hazardous Waste Research, 1999, 27-40

8. Daifullah A A M and Girgis B S, Water Res. 1998, 32(4), 1169-1177

9. Daifullah A E H and Gad H, Adsorp. Sci. Tech. 1998, 16(4), 273-283

10. Ravi V P and Jasra R V, J. Chem. Technol. Biotechnol 1998, 71(2), 173-179

11. Ru- Ling T, Feng- Chin W and Ruey-Shin J, Carbon, 2003, 41, 487-495

12. Edwin Vasu A, E-J.Chem. 2007, 5, 1-9.

13. Giles C H, MacEwan T H, Nakhwa S N and Smith D. J. Chem. Soc. 1960, 4, 3973-3993.

14. Redlich O and Peterson D L, J. Phys. Chem. 1959, 63, 1024

15. Treybal R E, Mass-Transfer Operations, McGraw-Hill Publishers, New York, 1980.

16. Conney D O, Adsorption Design for Wastewater Treatment, CRC Press LLC: Boca Raton, FL, 1999.

17. McKay G, Otterburn M S and Sweeny A G, Wat. Res. 1980, 14, 21-27.

18. Ho Y S. Adsorption, 2001, 7, 139-147.

19. Ho Y S, J. Colloid Interface Sci., 2003, 262, 307-308.

20. Thirunavukkarasu O S, Viraraghavan T, Subramanian K S and Tanjore S, Urban Water, 2002, 4, 415-421.

21. Low M J D, J. Chem. Soc. 1960, 267-312

22. Ho Y S and McKay G, A, Trans. IChemE B, 1998, 76, 332-340 


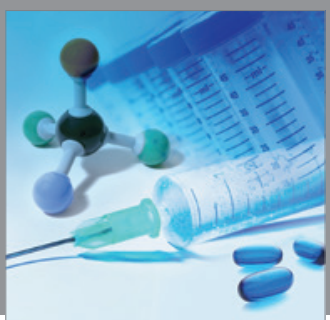

International Journal of

Medicinal Chemistry

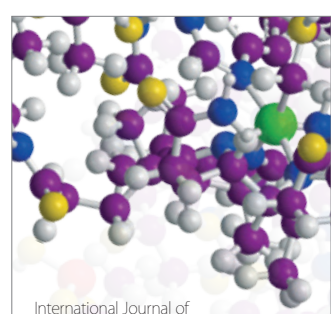

Carbohydrate Chemistry

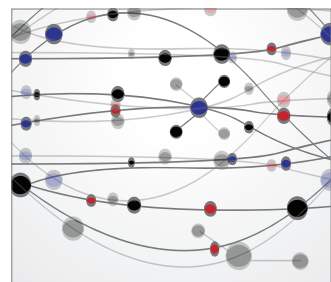

The Scientific World Journal
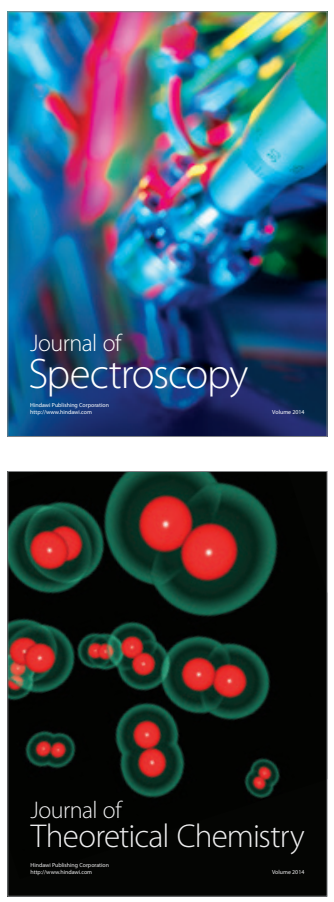
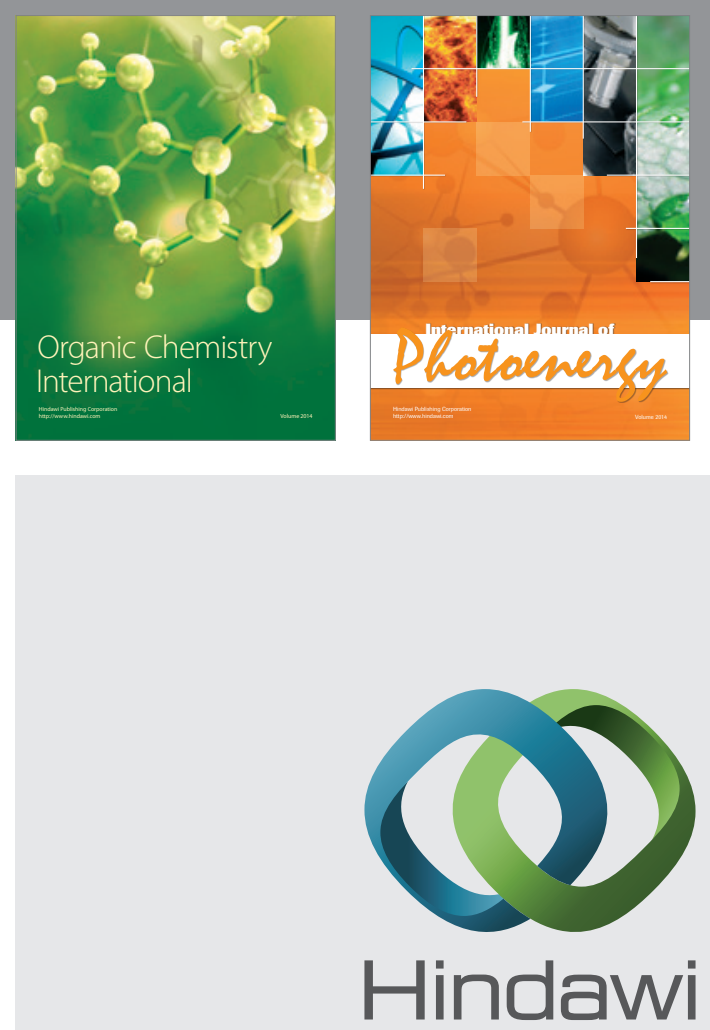

Submit your manuscripts at

http://www.hindawi.com
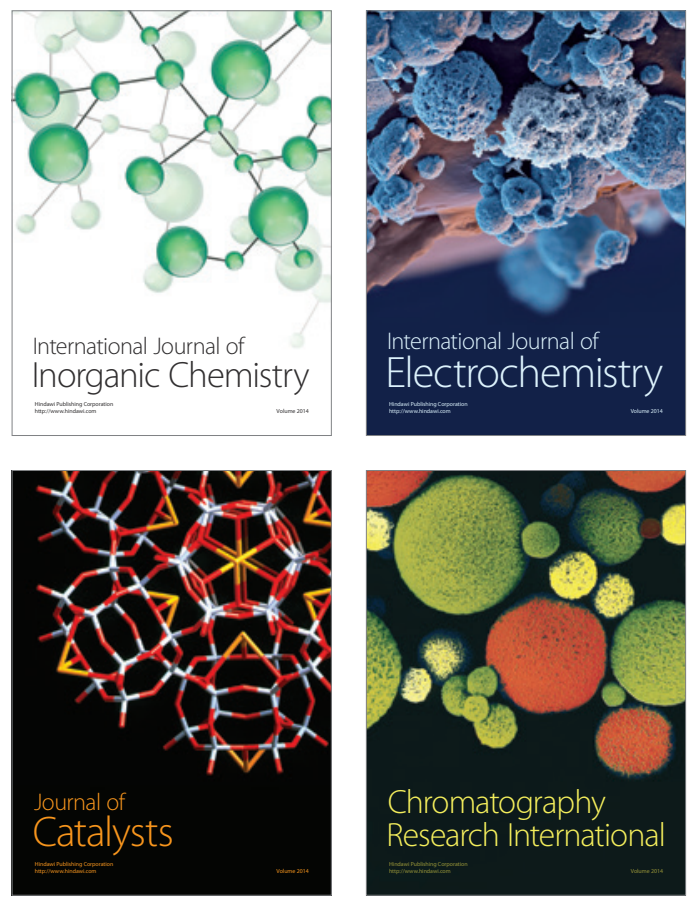
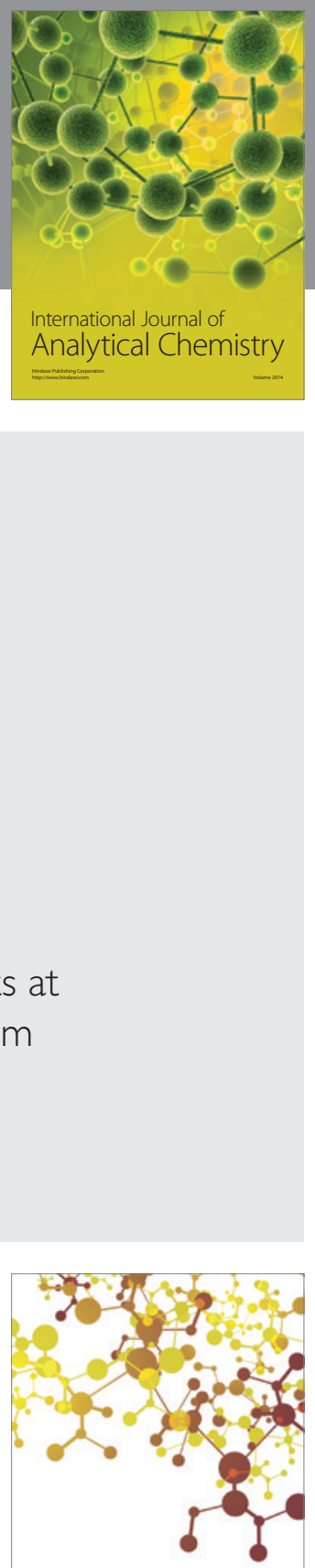

Journal of

Applied Chemistry
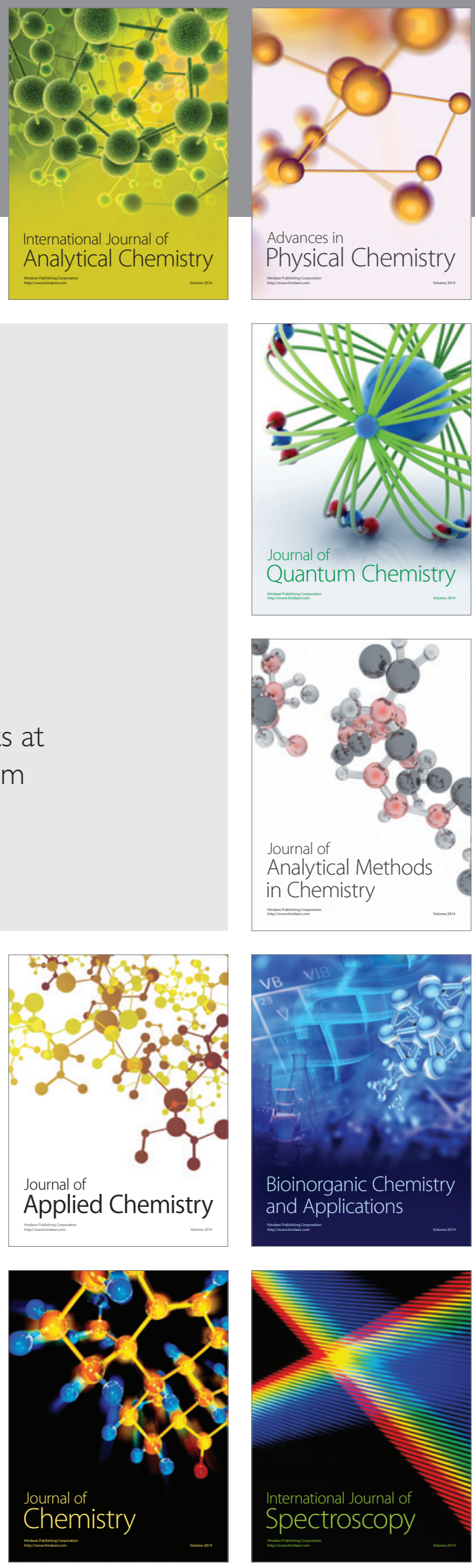